\title{
Hysterosalpingographic patterns and relevance in the management of infertility in a Nigerian tertiary health Institution
}

\author{
D U Eduwem', A O Akintomide ${ }^{2}$, D E Bassey ${ }^{3}$, M I Ekott ${ }^{4}$ \\ ${ }^{1,3}$ Associate Professor, Department of Radiology, ${ }^{2}$ Senior Lecturer, Department of Radiology, ${ }^{4}$ Associate Professor, \\ Department of Obstetrics and Gynaecology, Faculty of Medicine and Dentistry, University of Calabar
}

Background: Infertility is a major clinico-social problem not only in Nigeria; but the whole of the sub-saharan Africa and other parts of the world. In Nigeria it accounts for over $50 \%$ of attendance in Gynecological clinics. Hysterosalpingography (HSG) is still a very valuable imaging modality in the work-up of women with infertility; especially in some communities in Nigeria where modern non-invasive diagnostic modalities are not readily available in most of the health institutions. Aims and Objectives: The study aims at evaluating the HSG findings among women with infertility to further highlight the relevance of this imaging modality in the management of infertility. Materials and Methods: A retrospective review of 205 consecutive Hysterosalpingograms from the University of Calabar Teaching Hospital between October 2013 and September 2015 was done. The Radiological findings and demographic data of the patients were documented and analyzed. Results: Pathologies were reported on 176 (85.8\%) Hysterosalpingograms while $29(14.14 \%)$ were normal. The age range of the patients was between 21 and 55 years and the commonest age group was 31 - 35 years. The commonest pathological findings were in the uterus; namely uterine fibroids, 86 (41.95\%), uterine synaechiae, 19 (9.26\%), Asherman syndrome and congenital abnormalities, 5 each $(2.43 \%)$. The next commonest pathologies were those associated with tubal occlusions. Conclusion: Hysterosalpingography still plays a major investigative role in the evaluation and management of women with infertility. The commonest abnormalities seen in this study were in the uterus.

Key words: Infertility, Hysterosalpingogram, Fibroids, Tubal Occlusion
Access this article online

Website:

http://nepjol.info/index.php/AJMS

DOI: 10.3126/ajms.v7i5.15169

E-ISSN: 2091-0576

P-ISSN: 2467-9100

\section{INTRODUCTION}

The World Health Organization (WHO) defines infertility as "a disease of the reproductive system defined by the failure to achieve a clinical pregnancy after 12 months or more of regular unprotected sexual intercourse."1

In most parts of the world, infertile couples, especially the women suffer physical and mental abuses, neglect, economic deprivation and social ostracism. ${ }^{2,3}$ Detecting the cause of infertility and its successful management to achieve the desired result (pregnancy), brings much joy to couples and families and has been shown to strengthen marriages.
Despite the availability of an array of diagnostic modalities such as Ultrasound (US), Magnetic Resonance Imaging (MRI), Hysteroscopy and Laparoscopy, Hysterosalpingography (HSG) is still a very valuable tool in the work-up of women with infertility. $80-$ $93 \%$ of these women show one form of abnormality or another on HSG..$^{4-6}$ It is still a first line investigation in the evaluation of tubal patency. ${ }^{9,10}$ Other diagnostic modalities are either not readily available in most of our local centres, or they may be less insensitive, with reduced resolution and definition especially in detecting tubal abnormalities which many studies have shown to contribute between $30-40 \%$ to the problem of infertility in women. ${ }^{7-10}$ HSG's sensitivity and specificity 
are estimated at $65-81 \%$ and $47-50 \%$ respectively for tubal pathologies. ${ }^{11,12}$

Tubal factors commonly detectable at HSG include complete or partial occlusions, chronic salpingitis, Hydrosalpinx and peritubular adhesions. ${ }^{10-12}$ Uterine abnormalities include congenital abnormalities, polyps, fibroids, adhesions and adenomyosis. ${ }^{8,10}$ They are said to account for about $10 \%$ of infertility in women and $50 \%$ of women with recurrent early pregnancy loss. ${ }^{13}$

While some clinicians would prefer non and less invasive diagnostic procedures to HSG. ${ }^{14}$ Some patients decline to carry out the investigation either due to increasing high cost or fear of pain. ${ }^{15,16}$

This study therefore aims at highlighting HSG findings in cases of infertility in our environment in other to sensitize the clinicians to the benefits and relevance of the investigation in the planning and management of infertility.

\section{MATERIALS AND METHODS}

Two Hundred and Five (205) consecutive Hysterosalpingograms and their attached request forms from the Radiology Department of the University of Calabar Teaching Hospital between October 2013 and September 2015 were retrieved and reviewed.

Patient's bio-data, indications for HSG and the radiological findings were documented and analyzed using Microsoft Spreadsheet and subjected to descriptive statistical analysis using SPSS version 18.

\section{RESULTS}

Age range was between 21 and 55 years with a mean of 36 years (Table 1). The commonest age group was 31 - 35 years with a total number of $66(32.19 \%)$. Out of the 205 cases reviewed; 29 (14.14\%) had normal findings while 176 (85.8\%) showed abnormalities.

Uterine pathologies were the commonest abnormalities and accounted for 115 (56.10\%) (Table 2). Of these, uterine fibroids were the most documented uterine abnormalities; accounting for $86(41.95 \%)$ of all the cases. Majority, $62(30.24 \%)$ were intramural or sub serous, presenting as uterine cavity enlargement, distorted or irregular outline and displacement of the cavity. The remaining $24(11.71 \%)$ were sub mucous, presenting mainly as rounded or irregularly shaped marginal, central or fundal filling defects. Uterine Synaechiae was documented in $19(9.26 \%)$ cases while

\begin{tabular}{lcc} 
Table 1: Age range of subjects & \\
\hline Age range (years) & Number & Percentage \\
\hline $21-25$ & 12 & 5.88 \\
$26-30$ & 28 & 13.65 \\
$31-35$ & 66 & 32.19 \\
$36-40$ & 45 & 21.95 \\
$41-45$ & 42 & 20.48 \\
$46-50$ & 11 & 5.36 \\
$50-55$ & 1 & 0.48 \\
$\mathrm{n}=205(100 \%)$ & & \\
\hline
\end{tabular}

\section{Table 2: HSG findings}

\begin{tabular}{lcc}
\hline Findings & Number & Percentage \\
\hline Cervical abnormalities & 4 & 1.95 \\
$\quad$ Cervical stenosis & 3 & 1.46 \\
Cervical polyp & 8 & 3.90 \\
Patulous cervix & 15 & 7.32 \\
& & \\
Uterine abnormalities & 5 & 2.43 \\
$\quad$ Congenital abnormalities & 19 & 9.26 \\
$\quad$ Uterine synaechiae & 5 & 2.43 \\
$\quad$ Asherman's syndrome & & \\
Uterine fibroid & 62 & 30.24 \\
i: Intramural/subserous & 24 & 11.71 \\
ii: Submucous & 115 & 56.10 \\
& & \\
Tubal abnormalities & 30 & 14.63 \\
$\quad$ Tubal occlusion with hydrosalpinx & 21 & 10.24 \\
$\quad$ Tubal occlusion without hydrosalpinx & 10 & 4.87 \\
Hydrosalpinx without tubal occlusion & 4 & 1.95 \\
Chronic salpingitis without hydrosalpinx & 65 & 31.70 \\
& 21 & 10.24 \\
Pelvic adhesion & 29 & 14.14 \\
Normal HSG & & \\
n=245 & & \\
\hline 40 (19.5\%) HSGs had multiple pathologies &
\end{tabular}

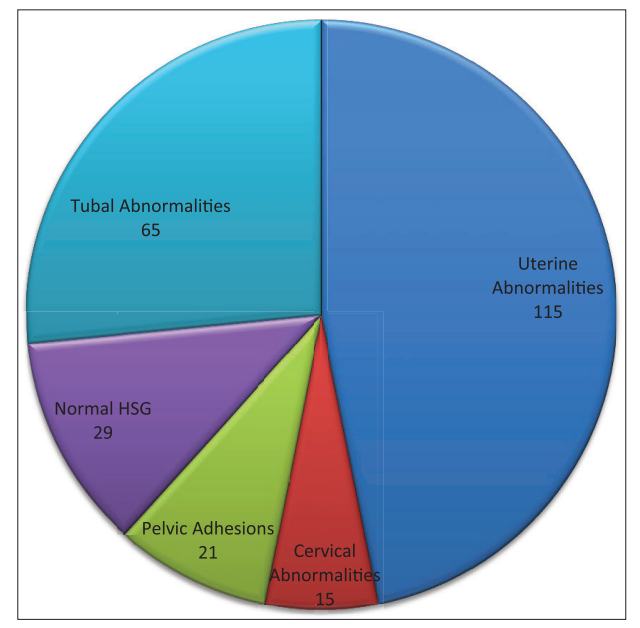

Pie chart showing distribution of hsg findings

congenital abnormalities of the uterus and Asherman's disease were the least uterine abnormalities.

The next most common group of pathologies were seen in the Fallopain tubes with $65(31.7 \%)$ of the reviewed 
hysterosalpingograms. They were mostly tubal occlusions and hydrosalpinx.

Pelvic adhesions accounted for 21 (10.24\%) of the reviewed radiographs. Multiplicity of lesions accounted for the 245 pathologies seen in the 205 cases reviewed; with 40 (19.5\%) hysterosalpingograms showing multiple abnormalities.

\section{DISCUSSION}

Infertility poses a global health and social challenge. ${ }^{1-3}$ In Nigeria, $50 \%$ of women attending Gynecological clinics complain of infertility. ${ }^{2,8}$ As seen in this study, 176 (85.8\%) out of the 205 cases reviewed showed abnormalities. This is almost similar to a study in Ilorin, North Central Nigeria, where $93 \%$ of the cases had abnormalities. ${ }^{8}$ Many other studies within Nigeria also indicate a high percentage of abnormalities among infertile women referred for HSG., Most cases of infertility are associated with pathologies causing partial or complete distortion of the uterine cavities

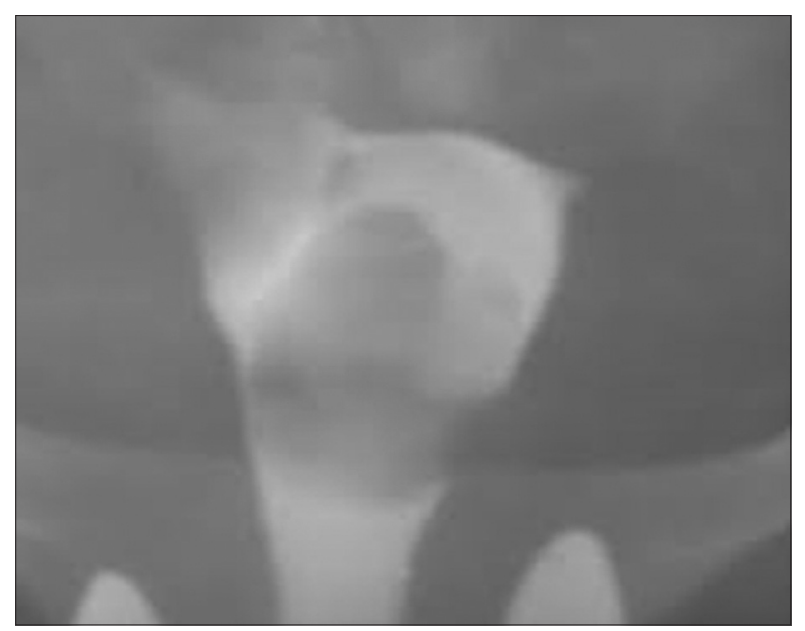

Figure 1: Submucous uterine fibroid

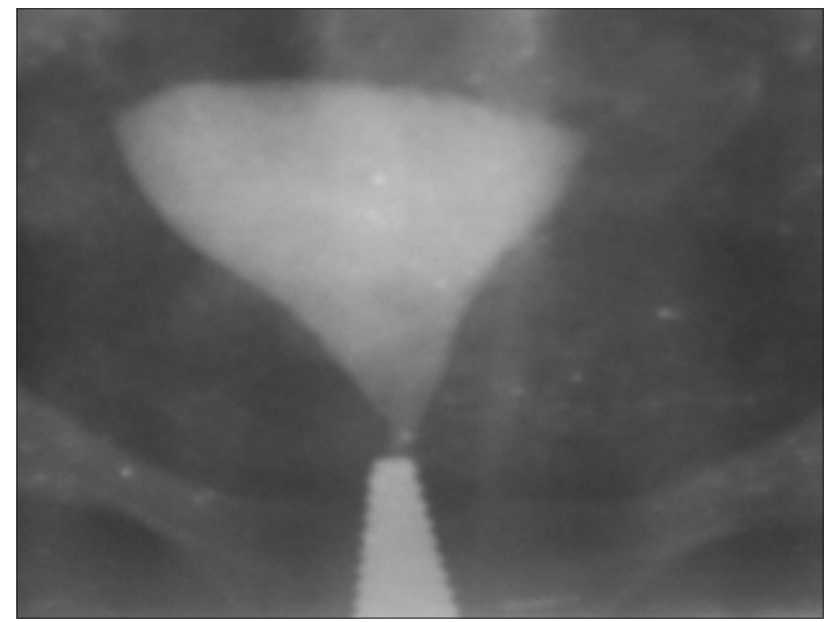

Figure 2: Bilateral Tubal Blockage and the occlusion of the fallopian tubes. HSG clearly outlines this reproductive pathway and thus a very valuable tool in the investigation of infertility.

Our study reveals that women in the reproductive age groups (26-30, 31-35, 36-39) had the highest number of referrals (Table 1). This is in keeping with the high reproductive demand in this age groups. ${ }^{10}$ The minimum age seen was 23 years compared to studies in Northern Nigeria with a minimum age of 17 years. This has to do with the socio-cultural background in the North where early marriages are common. ${ }^{13,17}$

The commonest abnormalities in our study were of uterine origin (Table 2). Of these, uterine fibroid constituted $41.95 \%$. Most of them were intramural or sub serous in location $(30.24 \%)$ while the rest were sub mucous. This high incidence of uterine fibroids on HSG is similar to findings in South Eastern Nigeria by Mgbor (50\%), ${ }^{18}$ whereas a much lower incidence $(5.9 \%)$ was reported in Northern Nigeria. ${ }^{17}$

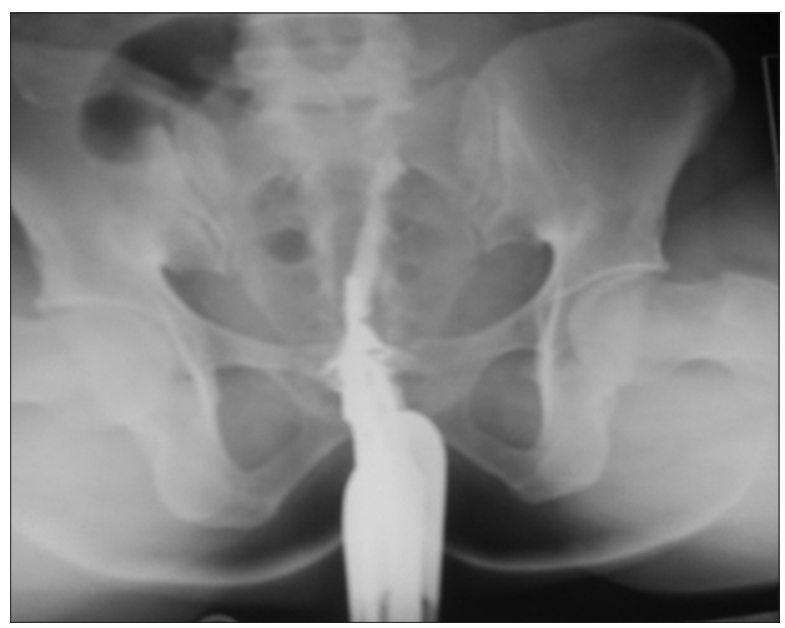

Figure 3: Severe case of Asherman's Disease

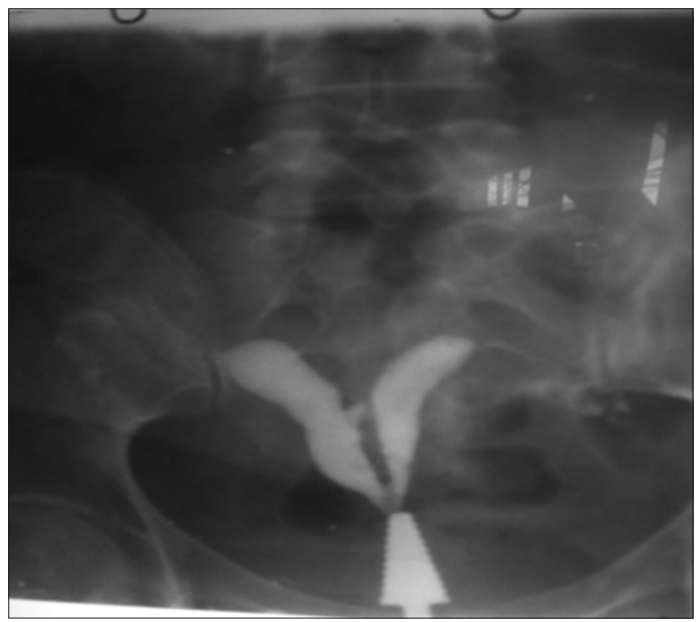

Figure 4: Bicornuate Uterus (Uterus BicornisUnicollis) 


\begin{tabular}{lcc}
$\begin{array}{l}\text { Table 3: Relationship between age group and } \\
\text { frequency of uterine fibroids }\end{array}$ \\
\hline Age range (years) & Frequency & Percentage \\
\hline $21-25$ & 2 & 2.08 \\
$26-30$ & 16 & 16.67 \\
$31-35$ & 32 & 33.33 \\
$36-40$ & 34 & 35.42 \\
$41-45$ & 12 & 12.50 \\
$46-50$ & 0 & 0 \\
$51-55$ & 0 & 0 \\
Total & 96 & 100 \\
\hline
\end{tabular}

In our study, Fibroid associated abnormalities were commoner in the $36-40$ age group (Table 3). This agrees with the general assertion that uterine fibroids are commoner with increasing reproductive age and lower parity. ${ }^{19,20}$ Apart from the difficulties in achieving pregnancy, uterine fibroids, especially the sub mucous varieties (Figure 1), result in marked distortion and enlargement of the uterine cavity and are commonly responsible for repeated first and second trimester abortions. ${ }^{19-22}$ A study in Ghana ${ }^{19}$ observed that as age advanced, the number of patients with fibroids also increased but decreased after 40 years. This association was found to be statistically significant \{contingency coefficient (cc) $0.21, \mathrm{p}>0.001$ \} . Our young women should therefore be encouraged to marry in their mid-twentiesafter completing their higher education and start having children thereafter.

Tubal pathologies were the second most common abnormalities seen in this study, accounting for $31.70 \%$. Most studies in Nigeria, and indeed other parts of the world however have tubal pathologies as the most common abnormalities. ${ }^{20,23-25}$ They present as bilateral (Figure 2), unilateral tubal occlusions with or without hydrosalpinx as well as peritubular adhesions.

Pelvic infections are the commonest cause of tubal pathologies. Most of them result from poorly treated sexually transmitted disease like Gonorrhea and Clamydia infections. ${ }^{13,17}$ Puerperal sepsis and other post-surgical complications involving the uterus and other pelvic organs have also been implicated. ${ }^{24}$ Primary preventive measures as well as prompt proper treatment of pelvic infections must be encouraged in order to reduce the high incidence of infertility resulting from tubal abnormalities.

Of particular interest is the high percentage $(9.26 \%)$ of uterine synaechiae seen in our study. This is in contrast to other studies (5\% Benin, $4.5 \%$, Sokoto). ${ }^{6,17}$ Complete uterine adhesion (Asherman's syndrome) (Figure 3) was seen in $5(2.43 \%)$ patients. These abnormalities present as filling defects and narrowing of the cavity on HSG and are known to be associated with previous repeated surgeries involving the uterine cavity. ${ }^{26,27}$
The main congenital abnormalities seen in our studies were bicornuate uterus, $2.43 \%$ (four mild cases in arcuate form, and one case of uterine bicornisunicollis - Figure 4). Congenital abnormalities are uncommon worldwide with most studies recording similar low percentages. They are however frequently associated with repeated miscarriages. ${ }^{11,19,27}$

A major limitation of this study was its retrospective radiological centre-based analytical design hence important clinical data especially relating to parity, previous treatment/surgeries could not be obtained. It must also be stated that the technique of HSG as presently carried out in our centre is not completely in line with current imaging best practices. Imaging under Fluoroscopy, use of disposable plastic cannular, sono-HSG, HyCoSy, Hysteroscopy and Laparoscopy are options that should be explored.

\section{CONCLUSION}

Although there is an array of modern, less invasive diagnostic modalities for monitoring women with infertility worldwide, some of these facilities are not available in most hospitals in Sub-Saharan Africa. This study reveals that a high percentage of infertile women in Calabar, Nigeria have abnormal HSG findings, hence the investigation still plays a major role in the evaluation and subsequent management of women with infertility. The commonest abnormalities in our study were noted in the uterus; especially those associated with uterine fibroids.

\section{RECOMMENDATION}

We recommend that the Nigerian Government should equip our secondary and tertiary health institutions with modern non-invasive and more sensitive diagnostic imaging modalities to help physicians manage the scourge of infertility with minimal discomfort to the patients.

\section{ACKNOWLEDGMENT}

We wish to gratefully acknowledge the efforts of Miss Priscilla Effiong Monday for painstakingly typing out the manuscript.

\section{DECLARATION}

We wish to declare that this project is solely funded by the authors and there is no conflict of interest. 


\section{REFERENCES}

1. WHO. ICMART revised Glossary. Sexual and reproductive Health: Fertility and Sterility 2009;Vol 92, No. 5.

2. Onufus FE, Harries D, Odebiyi A, Kare T and Snow RE. The Social Meaning of Infertility in Southwest Nigeria. Health Transition Review 1997; Vol 7(2): 205-220.

3. Tara $M$ and Domar AD. Psychological Impact of Infertility. Science Direct Best Practice and Research, Clinical Obstetrics and Gynaecology 2007; 21 (2): 293-308.

4. Ubeda BM, Paraiza M, Alert $E$ and Abuin RA. Hysterosalpingography: Spectrum of normal variants and nonpathological findings. AJR 2010; 177 (1):131-135.

5. Ibekwe PC, Udesi AM and Imo AO. Hysterosalpingographic Findings in Patients with infertility in South Eastern Nigeria. Nigerian Journal of Medicine 2010; 19 (2):165-167.

6. Eze CU, Ohagwu CC, Abonyi LC, Njoku J, Irurhe NK and Igbenedion FO. A spectrum Hysterosalpingographic Findings in Infertile women in Benin City, Nigeria. Journal of Reproduction and Infertility 2013; 4 (2):13-18.

7. Dalfo AR, Ubeda B, Ubeda A and Monzon M. Diagnostic Value of HSG in the Detection of Intra-uterine Abnormalities. A comparison with Hysteroscopy. AJR 2004; 183: 1405-1409.

8. Oguntoyinbo $A E$ and Aboyeji AP. Hysterosalpingographic (HSG) Findings of Infertile Patients in Ilorin. Trop J Obstetrics Gynaecology 2010; 29 (1):118-125.

9. Practice Committee of American Society for Reproductive Medicine. Diagnostic evaluation of infertile women; a committee opinion. Fertility Sterility 2012; 98:302.

10. Lim CP, Hasata Z, Bhacharya S and Maheshwari A. Should Hysterosalpingogrambe a first live investigation to diagnose female tubal sub-fertility in the modern fertility work-up? Human Reproduction 2011; 26:967.

11. Sakar MN, Gul T, Ateng AE and Celi KT. Hysterosalpingography and Laparascopy in the evaluation of infertile women. Saudi Medical Journal 2008; 9 (9): 1315-1318.

12. Heis $M$, Amarun $Z$, Ibrahim $A Y$, Obeidat $N$ and Omori $M$. Uterine and Tubal Anatomical abnormalities in infertile women: diagnosis with routine Hysterosalpingography prior to selective Laparascopy, South Africa Journal of Radiology 2011;15 (4):120-122.

13. Danfulam M, Mohammed MS, Ahmed SS and Haruna YG. Hysterosalpingographic Findings in women with infertility in Sokoto, North West Nigeria. African Journal of Medical and
Health Sciences 2014; 13 (1): 19-23.

14. Ugwu AC, Obi L, Imo AO and Umeh EC. Hysterosalpingography as a work-up tool in Infertility; Exploring Clinicians views Research 2015; 1:770.

15. Bara DH. Taking Fear out of HSG. Centre for Human Reproduction, 2014; Vol 2.

16. Mgbor SO, Ezegwui HU, Obikili E, Ikeme AC and Onuh AC. Perception of Hysterosalpingogram by Infertile women in a Developing Country. Journal of Obstetrics and Gynaecology 2005; 25 (5): $504-505$.

17. Bukar M, Mustapha Z, Takal UI and Tahir A. Hysterosalpingographic Findings in Infertile women. A seven year review. Nigerian Journal of Clinical Practice 2011; 14(2): 168-170.

18. Mgbor SO. Pattern of Hysterosalpingographic Findings among Gynaecological patients in Enugu, Nigeria. Medical Journal 2006; 47: 14-16.

19. Botwe BO, Bamfo-Quaicoe K, Hunu E, Anim-Sampong S. Hysterosalpingographic findings among Ghanaian women undergoing infertility work-up: A study at the korle-Bu Teaching Hospital. Fertility Research and Practice 2015; 1 (9):1-6.

20. Olutu EJ, Osunwoke EA, Ugboma HA and Odu KN. Age Prevalence of Uterine Fibroids in South-South Nigeria; A retrospective study. Scientific Research and Essay 2008; 3 (9): 457-459.

21. Bayekare N, Li TC. Fibroids, infertility and pregnancy wastage. Human Reproduction update 2000; 6 (6):614-620.

22. Casim' ML, Rossi F, Agostini R and Unfer V.Effects of the position of Fibroids on Fertility. Gynaecological Endocrinology 2006; 22(1): 106-109.

23. Eleje GU, Okaforcha EI, Umeonunihu OS, Udegbunam OI, Etoniru IS and Okwuosa AO. Hysterosalpingographic Findings Among Infertile Women: Review at a Tertiary Healthcare Institution in Nnewi; South East Nigeria. Afrimedic Journal 2012; 3 (2): 20-23.

24. Kiridi K, Ibrahim IA and Lawani L. Hysterosalpingography; still relevant in the evaluation of infertility in the Niger Delta. International Journal of Medicine and Biomedical Research 2015; 4 (1): 51-54.

25. Facts Sheets: Intrauterine Adhesions American Society for Reproductive Medicine, 2012 Edition.

26. Tuuli MG, Shanks A, Bernhard L, Odibo AO, Macores GA and Cahilla A. Uterine Synaechiae and Pregnancy Complications. ObstetGynaecol 2012; 119 (4): 810-814. 